\title{
EL SACERDOTE ANCIANO: CRITERIOS PARA SU VIDA Y SU PASTORAL
}

DOI: https://doi.org/10.52039/seminarios.v56i197-198.401

\author{
OVIDIO PECHARROMÁN ${ }^{1}$
}

\begin{abstract}
A sus setenta y cuatro años, el autor nos ofrece estas páginas, breves pero condensadas, que hace circular entre la teoría y la experiencia propia. Son criterios de vida que ha formulado para sí, y desea presentar a la consideración de otros sacerdotes que se encuentran también ante esta -también crucial- etapa de su vida personal.
\end{abstract}

La cuerda metodológica que sostiene el peso del argumento del sucinto ensayo que sigue se articula en cuatro hilos que se entretejen:

-El hilo de la sabiduría popular sobre la vejez, que se expresa en forma de dichos, refranes y sentencias a nivel mundial.

-La experiencia personal de vejez del propio autor del artículo.

-Modestas interpretaciones filosóficas en la línea de la antropología.

-Finalmente, aspectos de sonido estadístico y académico cortésmente aceptados como subsidiarios.

En camino sobre esta «desconfiable» cuerda metodológica es como, penosamente, hemos llegado a esa orilla de criterios sobre la forma de cristalización de la vejez. Llevamos, pues, siempre la cartografía de lo opinable en la mano. Conocemos, creo, relativamente poco todavía acerca de la «fórmula de la vejez» del ser humano. Por eso ofrecemos, con cierto grado de temblor, la lista de criterios que sigue, a modo de espejo, en el que pueda contemplarse el sacerdote anciano con miras a su pastoral de vejez.

Criterio número 1: Mi persona. Como sacerdote, me es claro que soy yo mismo quien representa los cuatro actos del drama de la vida: niño, joven, adulto, anciano; y, ahora, de modo especial, el último con todo cuanto la modalidad anciano porta consigo.

Criterio número 2: Libertad. Entiendo la vejez como uso razonable de la libertad, que ahora se expresa de forma paciente, poseída y benevolente. Creo que mi vejez es un tiempo de la vida que da la oportunidad de considerar la na-

1. Sacerdote Operario Diocesano. Ha sido director del Apostolado Hispano de la Diócesis de Arlington (Virginia, EEUU). En la actualidad dirige el Sol Vocational Institute que la Hermandad de Sacerdotes Operarios tiene en Washington D.C. Es autor de varias obras sobre evangelización, misión y psicología de la vocación cristiana. 
turaleza, la sociedad de los hombres y la misma persona, como «realidades a distancia», y conocidas ya a altura apropiada de contemplación sabia. Solo desde esta altura, experimentada, se logra la alegría de relativizar y poner en su sitio un buen número de aspectos del vivir. La libertad madura, establece una piedra de toque en la existencia de la persona anciana.

Criterio número 3: Decisión. Sé que la única manera de prolongar mi vida es en forma de vejez, actuando el cuarto acto del drama de mi existencia. $Y$ quiero actuarlo bien; de modo racional y profundamente cristiano.

Criterio número 4: Servicio. Quiero vivir la ancianidad como servicio bondadoso, espontáneo y humano a la vida -niña, joven y adulta-, mediante el consejo, la afirmación, la disculpa y el recuerdo del más allá. Y veo la vejez como ese tramo de la vida donde se esboza la sonrisa bien labrada, auténtica y sumisa. Esta sonrisa insiste y apoya sobre la convicción personal de que mi vivir mismo va bien orientado.

Criterio número 5: Alternativa. Sé que puedo aceptar libremente la vejez, o puedo vivir negándola. Aceptarla, me parece la alternativa más razonable. Por otra parte, el yo del anciano ha desvelado ya «los encantos» y existe como libre desencantado. Aun en la sociedad, vivamente imaginativa de hoy.

Criterio número 6: Identidad. La identidad del anciano posee una inclinación interior que le empuja a la trascendencia y hacia Dios. El anciano, consciente de esta propensión, alberga una alegría a la que acompañan penas, mayores y menores. Sabe, en efecto, que el enemigo de la alegría no es el dolor, sino la desesperanza, no tener nada en que fijar los ojos con interés profundamente personal.

Criterio número 7: Alegría. La alegría propia del anciano no es la del joven, o la del adulto, sino una alegría específicamente suya, adaptada, o mejor, rezumada de la vejez misma. Por otra parte, las oportunidades de bienestar que la sociedad actual proporciona al anciano, pueden actuar como amables provocadores de su alegría. Nosotros, los ancianos, distinguimos muy bien entre comodidad y alegría. La sociedad actual, a veces no.

Sabemos, efectivamente, que el mero distraer, entretener, o divertir no se identifica con el propósito de vivir; ni en la vejez -nuestra edad-, ni en otro cualquier acto del drama de la vida. La fórmula humana, en su verdad honesta, pide más que el confort en su departamento de deseos profundos.

Criterio número 8: Bienestar Social. La opinión pública social, para con el anciano, es mucho mejor hoy, 2011, que hace sólo 25 años. Y esta sociedad nuestra, a la que un servidor pertenece, presta una atención más cualificada al anciano, no sólo porque aumenta considerablemente su número fiscal, sino también porque oye la antigua voz histórica de la ternura y el merito que viajan en el barco social de siempre, y se instalan tozudamente en el timón mismo de las memorias colectivas, tan bellamente dichas por los refranes y sentencias de los pueblos. No nos hemos quedado atrás. Aunque, por supuesto, todavía no estamos contentos del todo con la labor hecha. 
Criterio número 9: Aceptación. Sé que el anciano que la sociedad acepta y quiere, posee los hábitos virtuosos de la prudencia, de la fortaleza, del obrar equilibrado y justo, y del obrar templado en todo. Y que semejante actuar es iluminado en el cristiano -cuanto más en los sacerdotes ancianos- por la luz de las constelaciones de la fe, la esperanza y la caridad que dan explicación final de su destino en la vida. Por el contrario, son incongruencias, quizás vicios en la ancianidad, vivir ésta sin haber superado el acto de la juventud, o el de «la madurez», por ejemplo. El vivir fuera de tiempo, es decir, de acto. Si fuera así, nuestra razón se asombraría ante la desproporción. Como nos produce también cierto asombro la conducta codiciosa, o la conducta impositiva, o viciosamente sexual en el anciano. Y nos intimida el viejo irascible y quejumbroso.

Criterio número 10: El Ideal. El anciano modelo, ideal, media justamente y se coloca en el espacio gris, amable, y abierto al crecimiento continuo que separa la página de incongruencias, de la página razonable y virtuosa; en ese camino otoñante de luces y sombras, que se aleja en el bosque de la vida.

Criterio número 11: Necesidades. El anciano necesita mucho ser tenido en cuenta; necesita amigos; necesita atención a sus necesidades de salud; necesita, con intensidad interna, clarificar las razones con que cuenta para seguir viviendo; necesita vivienda adecuada y relaciones familiares verdaderas. Finalmente, necesita atención y medios para responder a sus necesidades espirituales. Semejantes necesidades estuvieron presentes en los actos primero, segundo y tercero de su drama; pero algunos se sienten más intensamente y más específicamente en este cuarto y último de la vida.

Criterio número 12: Identidad personal. La identidad personal sigue siendo tema central en la vejez; a primera vista, parecen más relevantes e identificadores los tres primeros actos del drama que el último: la puerta que abre a la vida, frente a la puerta que cierra esta vida. $Y$ a nosotros, los ancianos, nos conviene mucho distinguir claramente entre puerta que se cierra y fin de la existencia. En efecto; la muerte deja aquí nuestra mortalidad, no nuestra inmortalidad. $Y$ el término no es el fin. Mientras tanto, el anciano es un ciudadano relevante, ya que establece una historia útil para sí mismo y para la comunidad. De aquí que la vejez sea ocasión propicia para dar lo recogido y entregarlo. Sabemos bien que es sólo el anciano quien hace testamento, no el niño.

Criterio número 13: Signos de los Tiempos. Estamos aquí para vivir los cuatro actos de eso que llamamos vida, y que experimentamos como realidad fluyente, «ex-istente». El punto de vista actual privilegia los fragmentos sobre el todo. $Y$ el cuarto acto de la vida tiende a juzgarlo como a parte, separado, independiente. Moviliza, en efecto, una preferencia de la parte sobre el todo. El criterio numero 1 , nos alertaba ya a este punto.

Criterio número 14: Anciano Cristiano. La Escritura pide a Dios que nos enseñe a contar nuestros días para que alcancemos un corazón sabio (Sal 90, 12). El anciano sabe que se encuentra al fin de la vida y a la orilla de la eterni- 
dad. Sobre esta base, el anciano cristiano se atreve a expresar su contento: "Que alegría cuando me dijeron, vamos a la casa del Señor». El viejo, pues, tiene razón para su alegría: su liberación está a la mano. Y esta esperanza de base le ayuda a contrarrestar la fuerza de la gravedad que pesa hacia abajo en las formas de insinuantes decaimientos y tristezas fragmentarias, ocasionadas por distintas razones. Una, no pequeña, es el pasado. Por esta proximidad a la llamada de Dios, el anciano actúa la benignidad de Dios sobre nosotros y aparece como planta sintética y global de la vida con buen olor a Cristo. Tal es la vejez cristiana; a pesar de que el Maestro no vivió la vejez.

Criterio número 15: Muerte. En el paisaje psicológico del anciano destaca mucho el árbol de la muerte. De aquí que la meditación y memoria de la muerte sea parte importante de la vejez. Por otra parte, es concebible que el hombre empiece a pensar en la muerte cuando algo, de hecho, ha muerto ya en él, o empieza a morir; cosa que ocurre bastante antes de la vejez «oficial».

Criterio número 16: Pastoral. Está por crear una pastoral del anciano, en una Iglesia cuyos bautizados envejecen. Esa pastoral podría apoyar en la paternidad amorosa de Dios; la psicología propia del anciano; su dignidad y filiación del padre; su ocupación razonable y caritativa. Tal insinuación, sugerida por J. Leclerc, contiene posibilidades de mucho interés.

Criterio número 17: En forma de Decálogo para el sacerdote anciano.

1. Reconoce los síntomas de tu vejez y acéptalos.

2. Atrévete a ser viejo.

3. Aprende a practicar tu vejez en tus seglares ancianos, y mediante largos espacios de oración contemplativa.

4. Admite el consejo.

5. Agradece mucho, afirma mucho, sirve mucho a las nuevas generaciones.

6. Sé activo, limpio, alegre y esperanzado.

7. Evita la amargura, el ostentar tu saber, la autocompasión y la impaciencia.

8. Huye de representar el acto del drama que no te corresponde y sé un icono de anciano, un anciano a tope.

9. Lo quieras o no, tendrás que ejercitar mucho el carácter, la fuerza de voluntad y la paciencia. No lo olvides.

10. No te alejes de la nave y estate prevenido para cuando seas llamado. Siente la alegría de la proximidad de la llamada.

Si haces esto, serás un pastor bueno y tiernamente querido como sacerdote anciano, donde quiera que estés. Y experimentarás la paz interna y la alegría. 